The 64th special issue "Frontiers of Carbon Materials"

\title{
Electrochemical Properties of Chlorine Dioxide Using Aminated Glassy Carbon Electrodes Fabricated by Electrolysis
}

\section{Motoyasu JINNAI, ${ }^{a}$ Chihiro SHIMAMURA, ${ }^{b}$ Satrio KUNTOLAKSONO, ${ }^{b}$ Yutaro TOKOYO, ${ }^{c}$ Susumu SATO, ${ }^{\mathrm{a}, \mathrm{d}}$ and Hiroaki MATSUURA ${ }^{\mathrm{b}, \mathrm{c}, *}$}

a Department of Information Systems, Graduate School of Engineering, Saitama Institute of Technology, 1690 Fusaiji, Fukaya, Saitama 369-0293, Japan

b Department of Life Science \& Green Chemistry, Graduate School of Engineering, Saitama Institute of Technology, 1690 Fusaiji, Fukaya, Saitama 369-0293, Japan

c Department of Life Science \& Green Chemistry, Faculty of Engineering, Saitama Institute of Technology, 1690 Fusaiji, Fukaya, Saitama 369-0293, Japan

d Department of Information Systems, Faculty of Engineering, Saitama Institute of Technology, 1690 Fusaiji, Fukaya, Saitama 369-0293, Japan

*Corresponding author: matsuura@sit.ac.jp

\begin{abstract}
Voltammetric properties of chlorine dioxide $\left(\mathrm{ClO}_{2}\right)$ obtained by using a glassy carbon (GC) electrode fabricated by electrolyzing in ammonium carbamate aqueous solution were first reported. GC electrode surface was covalently modified with nitrogen atoms containing functional groups, which were introduced onto GC surfaces by electrochemical oxidation process in ammonium carbamate aqueous solution. The introduction of nitrogen into the GC surface structure enhanced the electrocatalytic activities of GC electrode towards the electro-oxidation of $\mathrm{ClO}_{2}$ in an acidic medium more than a bare GC electrode does. A favorable linearity for the peak current signals in cyclic voltammograms was exhibited in the concentration range from 2.0 to $100 \mathrm{ppm}$.
\end{abstract}

(c) The Author(s) 2020. Published by ECSJ. This is an open access article distributed under the terms of the Creative Commons Attribution 4.0 License (CC BY http://creativecommons.org/licenses/by/4.0/), which permits unrestricted reuse of the work in any medium provided the original work is properly cited. [DOI: 10.5796/electrochemistry.20-64053]. Uploading "PDF file created by publishers" to institutional repositories or public websites is not permitted by the copyright license agreement.

Keywords : Nitrogen Atoms Containing Functional Groups, Electrochemical Modification, Chlorine Dioxide, Electrocatalytic Activity

\section{Introduction}

Glassy carbon (GC) has been widely used as an electrode substrate in various electrochemical fields since it has more sustainable chemical stabilities and wider potential window than those of metal electrodes such as gold and platinum have. ${ }^{1-3} \mathrm{GC}$ electrodes consisting of disordered carbon materials that are derived from polymers have been extensively utilized in the field of electrochemistry. The rich surface chemistries of GC electrodes play important roles for achieving good electrocatalysis, which allows GC electrodes to be a potential candidate for electroanalytical applications. ${ }^{4-6}$ In addition, the electrochemical activation of carbon electrode surfaces has attracted growing interest over several decades and their applications include electroanalytical chemistry. ${ }^{7,8}$ The chemical structures of carbon surface are significantly changed during the electrochemical modification reactions and consequently the interactions between materials with analytes are adapted. For example, it has been found that the reduction potential of oxygen can be significantly shifted to the potential of positive direction by using carbon alloy with nitrogen atoms. ${ }^{9}$

Recently, the authors' team has demonstrated that nitrogen atoms containing functional groups can easily be introduced onto GC electrode surface by the electrode oxidation of ammonium carbamate solution at a highly positive electrode potential, and we have named this electrooxidized GC electrode "an aminated GC (Am-GC) electrode". ${ }^{10}$ This electrochemical surface modification enables not only the primary amine group but also other nitrogen atoms containing functional groups to be introduced onto the GC electrode surface. ${ }^{11}$ The rates for electron transfer of various inorganic and organic compounds are accelerated to allow observation of excellent redox waves with Am-GC electrode. ${ }^{12,13}$ Hence, this electrochemical modification (amination reaction) of GC electrode surface improves the electrode kinetics and enhances electrocatalytic activities towards the redox reactions of some inorganic and organic compounds. ${ }^{14-16}$

Among the oxychlorine compounds with oxidative activity, chlorine dioxide $\left(\mathrm{ClO}_{2}\right)$ is known to be extremely potent. Due to the presence of one unpaired electron in its molecular orbital, ${ }^{17} \mathrm{ClO}_{2}$ is a free radical. ${ }^{18} \mathrm{ClO}_{2}$ is known to have potent antimicrobial ability against bacteria, viruses, and protozoa. ${ }^{19-22} \mathrm{ClO}_{2}$ has been used as a disinfectant for drinking water since it has strong oxidizing capability against various microbial proteins. Furthermore, Ogata and co-workers have reported that $\mathrm{ClO}_{2}$ inactivates the influenza virus. ${ }^{23}$ In addition, we expect $\mathrm{ClO}_{2}$ to also inactivate novel coronavirus (SARS-CoV-2) ${ }^{24}$ as well as the influenza virus.

Backed up by such biological importance of $\mathrm{ClO}_{2}$, the detection of $\mathrm{ClO}_{2}$ in water provides useful information for this purpose. Electrochemical sensing techniques for $\mathrm{ClO}_{2}$ were required to realize the above-mentioned application in practical fields. However, only few studies have focused on the electrochemical properties and electrochemical sensors of $\mathrm{ClO}_{2} \cdot{ }^{25}$ In addition, effects of surface nitrogen containing functional groups on facilitating electro activity of $\mathrm{ClO}_{2}$ have not been explicitly demonstrated.

In this paper, we report basic electrochemical properties of the Am-GC electrodes, which were studied by measuring cyclic 
voltammetry of $\mathrm{ClO}_{2}$ with different electron-transfer properties. The properties were also compared with results from a bare GC electrode. Moreover, we first demonstrated an electrochemical sensor based on voltammetric method of $\mathrm{ClO}_{2}$ using Am-GC electrode as a working electrode.

\section{Experimental}

Ammonium carbamate $\left(\mathrm{NH}_{2} \mathrm{COONH}_{4}\right.$, Merck, Germany), sulfuric acid $\left(\mathrm{H}_{2} \mathrm{SO}_{4}\right.$, FUJIFILM Wako Pure Chemical Corporation, Japan), and all other reagents were of analytical grade and were employed without further purifications. Chlorite ion $\left(\mathrm{ClO}_{2}^{-}\right)$ standard solution (certified standard solution for ion chromatography) was supplied by FUJIFILM Wako Pure Chemical Corporation (Japan). The test stock solution of chlorine dioxide $\left(\mathrm{ClO}_{2}\right)$ used was prepared by adding of the $\mathrm{ClO}_{2}{ }^{-}$into an acidic medium. Aqueous solutions were prepared with deionized water.

All electrochemical experiments were carried out in a conventional three-electrode cell constitution. An aqueous $\mathrm{Ag} / \mathrm{AgCl}$ (3 M $\mathrm{NaCl}$ electrolyte) electrode and a platinum wire were used as a reference and a counter electrode, respectively.

The Am-GC electrode was prepared by a constant potential electrolysis as follows. A bare GC electrode (BAS Co., Ltd., Japan; diameter of $3 \mathrm{~mm}$ ) was electro-oxidized in $0.1 \mathrm{M}$ ammonium carbamate aqueous solution at $+1.1 \mathrm{~V}$ (vs. $\mathrm{Ag} / \mathrm{AgCl}$ ) for 60 minutes at room temperature. This electrochemical modification process is one step with very simple and rapid modification of GC surface.

The electrochemical properties for $\mathrm{ClO}_{2}$ were carried out with an automation polarization system (HZ-3000, Hokuto Denko Co., Ltd., Japan) by cyclic voltammetry method. Voltammetric measurements of $\mathrm{ClO}_{2}$ were performed by using the bare GC electrode and the AmGC electrode prepared by the electrolytic-oxidation process described above.

\section{Results and Discussion}

We estimated electrochemical properties of the aminated GC (Am-GC) electrode in relation to chlorine dioxide $\left(\mathrm{ClO}_{2}\right)$ measurement. We also used a bare $\mathrm{GC}$ electrode to measure $\mathrm{ClO}_{2}$ for a comparison. Figure 1 shows cyclic voltammograms (CVs) of $10 \mathrm{ppm} \mathrm{ClO}_{2}$ in $0.5 \mathrm{M}$ sulfuric acid with the bare $\mathrm{GC}$ electrode and our Am-GC electrode measured under optimized conditions. In both cases, the redox wave between $\mathrm{ClO}_{2}$ and chlorate ion $\left(\mathrm{ClO}_{3}{ }^{-}\right)^{26}$ in the cyclic voltammograms was observed by using both electrodes in acidic medium. The electrode reaction of $\mathrm{ClO}_{2}$ has been expected as Eq. (1).

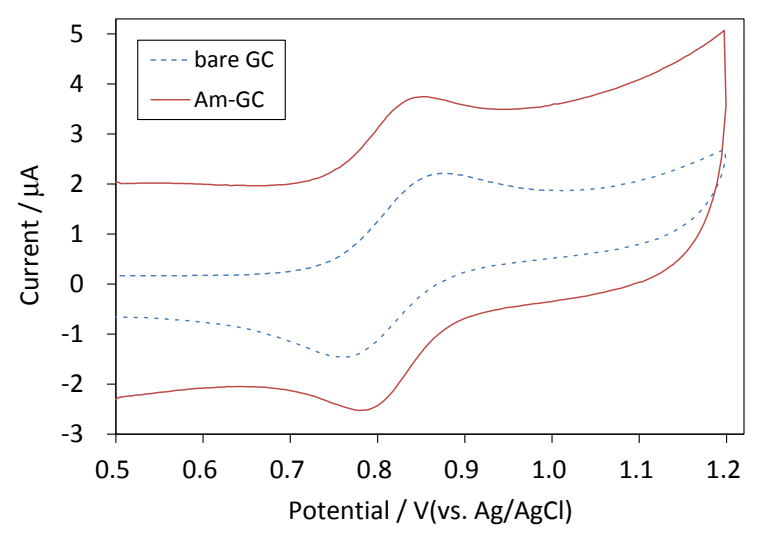

Figure 1. Comparison of $\mathrm{CVs}$ obtained by using bare $\mathrm{GC}$ electrode and Am-GC electrode recorded in $0.5 \mathrm{M}$ sulfuric acid containing $10 \mathrm{ppm} \mathrm{ClO}_{2}$. Sweep rate: $50 \mathrm{mV} \mathrm{s}^{-1}$.

$$
\mathrm{ClO}_{2}+\mathrm{H}_{2} \mathrm{O} \rightarrow \mathrm{ClO}_{3}^{-}+2 \mathrm{H}^{+}+\mathrm{e}^{-}
$$

In particular, the redox wave with the Am-GC electrode (solid line) is much clearer than that with the bare GC electrode (dotted line). Indeed, the peak separation $\left(\Delta E_{\mathrm{p}}\right)$ of $\mathrm{ClO}_{2}$ for the Am-GC electrode is $68 \mathrm{mV}$, which is obviously lower than $123 \mathrm{mV}$ for the bare GC electrode. This result indicates that the electron-transfer kinetics of $\mathrm{ClO}_{2}$ is significantly different between the Am-GC electrode and the bare GC electrode. Namely, electrochemical reversibility of $\mathrm{ClO}_{2}$ exhibits that our Am-GC electrode provides results that are comparable with those of the bare GC electrode. This may show that the nitrogen atoms containing functional groups introduced by electrode oxidation in ammonium carbamate aqueous solution function as electron-transfer mediators for $\mathrm{ClO}_{2}$ in acidic medium. With the Am-GC electrode, capacitance much higher than that of the bare GC electrode might be owing to the effect of nitrogen atoms containing functional groups introduced onto the GC electrode surface and to preparation of highly porous-structured GC electrode surface during the electrochemical surface oxidation process of the bare GC electrode in ammonium carbamate aqueous solution.

The redox wave of $\mathrm{ClO}_{2}$ was recorded at various sweep rates by $\mathrm{CVs}$ (Fig. 2a). The anodic peak current of $\mathrm{ClO}_{2}$ oxidation linearly increases with the square root of the sweep rate from $5 \mathrm{mV} \mathrm{s}^{-1}$ to $50 \mathrm{mV} \mathrm{s}^{-1}$ (Fig. 2b), which indicates that electrode oxidation reaction is a diffusion-controlled process of $\mathrm{ClO}_{2}$ in acidic medium. In addition, the measurement revealed that the electrode oxidation peak potential $\left(E_{\mathrm{pa}}\right)$ did not shift to a more positive potential direction with an increase in the sweep rate, which clearly indicates that the electrode oxidation reaction of $\mathrm{ClO}_{2}$ with Am-GC electrode is the reversible electrochemical reaction process.

The effect for electrolyte $\mathrm{pH}$ on oxidation peak potentials and oxidation peak currents of $\mathrm{ClO}_{2}$ with the Am-GC electrode were investigated by measuring cyclic voltammograms $(\mathrm{CVs})$ as shown in Fig. 3a. In the case that the electrolyte $\mathrm{pH}$ was lower than 2.5 , the shift of oxidation peak potentials of $\mathrm{ClO}_{2}$ towards more positive values were observed. Favorable linear relationship between the oxidation peak potential and $\mathrm{pH}$ value was observed for the slope values of $-37.6 \mathrm{mV}$ per $\mathrm{pH}$ for $\mathrm{ClO}_{2}$ (Fig. 3b). These facts suggest
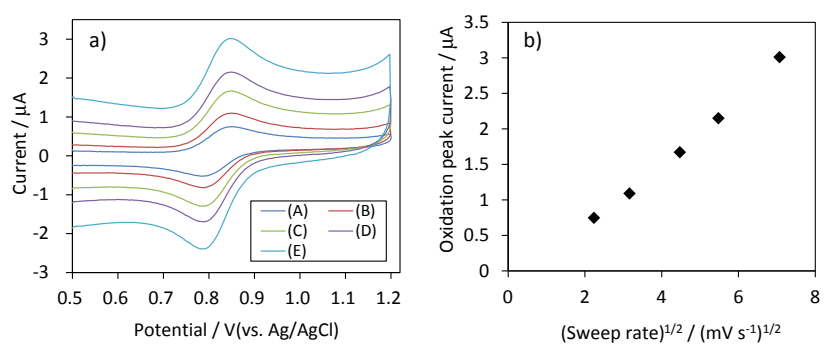

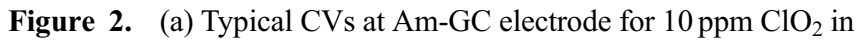
$0.5 \mathrm{M}$ sulfuric acid at different sweep rates (A-E): 5, 10, 20, 30 and $50 \mathrm{mV} \mathrm{s}^{-1}$. (b) The corresponding plots of oxidation peak current vs. square root of sweep rate for $\mathrm{ClO}_{2}$.
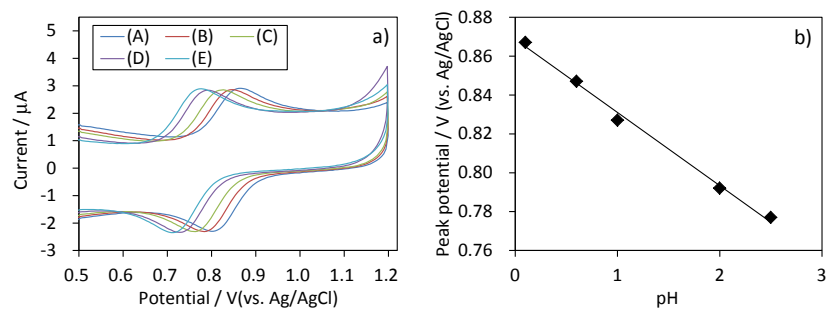

Figure 3. (a) $\mathrm{CVs}$ of $10 \mathrm{ppm} \mathrm{ClO}_{2}$ using $\mathrm{Am}-\mathrm{GC}$ electrode in different $\mathrm{pH}$ electrolyte (A-E): 0.1, 0.6, 1.0, 2.0 and 2.5. (b) The corresponding plots of their peak potentials vs. $\mathrm{pH}$ values. 


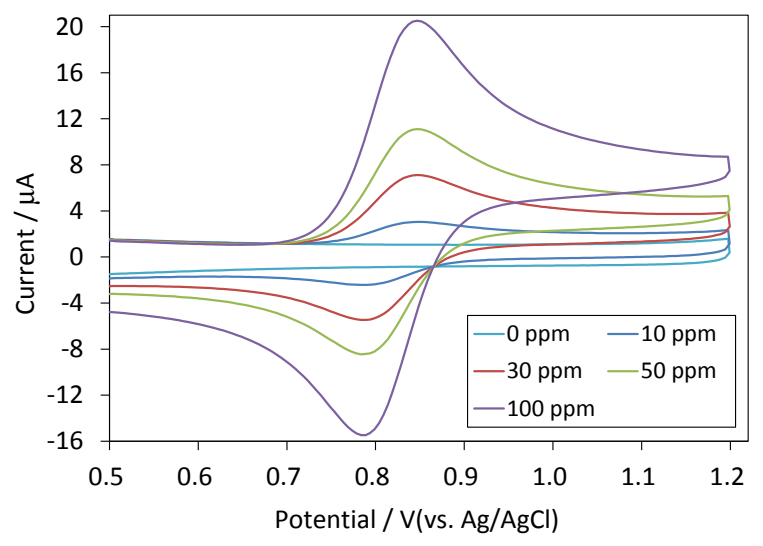

Figure 4. $\mathrm{CVs}$ of $\mathrm{Am}-\mathrm{GC}$ electrode in $0.1 \mathrm{M}$ sulfuric acid containing various concentrations of $\mathrm{ClO}_{2}$ in the range from 0 to $100 \mathrm{ppm}$.

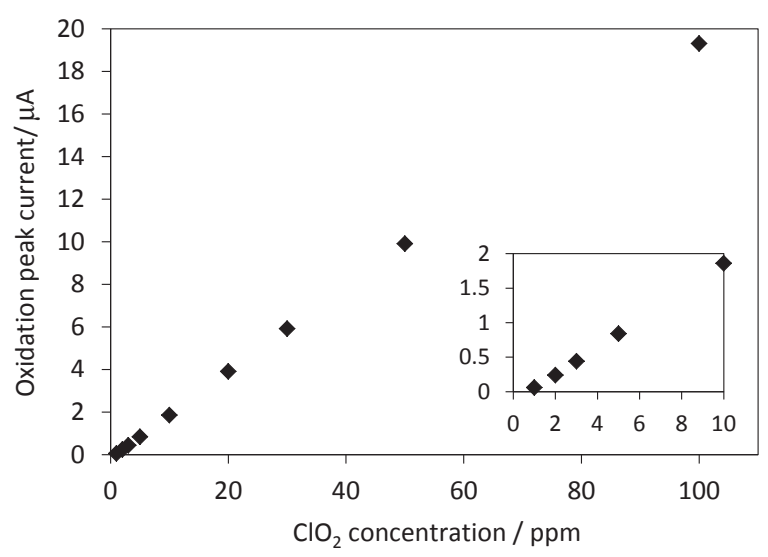

Figure 5. Calibration curves of $\mathrm{ClO}_{2}$ using the voltammetric measurements with the Am-GC electrode.

an electrode reaction of $\mathrm{ClO}_{2}$ coupled proton transfer electrode process. In addition, peak current values were similar under various electrolyte $\mathrm{pH}$ conditions. The $\mathrm{p} K_{\mathrm{a}}$ value of $\mathrm{HClO}_{2}$ (chlorous acid) was ca. 1.9. Over this electrolyte $\mathrm{pH}$ range, $\mathrm{HClO}_{2}$ and $\mathrm{ClO}_{2}{ }^{-}$ (chlorite ion) were dominant species with the loss of $\mathrm{ClO}_{2}$ owing to its chemical equilibrium. For these reasons, determination of $\mathrm{ClO}_{2}$ is suitable for acidic conditions (the electrolyte $\mathrm{pH}$ is lower than 2.5) of electrolyte.

Analytical performance of $\mathrm{ClO}_{2}$ was measured by voltammetric method for the Am-GC electrode in $0.5 \mathrm{M}$ sulfuric acid electrolyte as presented in Fig. 4. The oxidation peak current increased obviously with an increase in $\mathrm{ClO}_{2}$ concentration and the oxidation peak potential was almost unchanged (ca. $+0.85 \mathrm{~V}$ ). Therefore, an extremely stable electrochemical response of a $\mathrm{ClO}_{2}$ sensor is expected. The oxidation peak current of $\mathrm{ClO}_{2}$ was proportional to $\mathrm{ClO}_{2}$ concentration in the range up to $100 \mathrm{ppm}$ with favorable correlation coefficient as 0.997 (Fig. 5). The lower detection limit was found to be $2.0 \mathrm{ppm}$. Next, the Am-GC electrode proposed in this study was applied to a useful $\mathrm{ClO}_{2}$ analysis method since simple and rapid $\mathrm{ClO}_{2}$ in water concentration measurement was available.

\section{Conclusion}

We successfully demonstrated electrochemical properties of $\mathrm{ClO}_{2}$ using the GC electrode fabricated by electrolyzing in ammonium carbamate aqueous solution. Nitrogen atoms containing functional groups introduced onto GC surfaces by electrode oxidation of carbamic acid function as electron-transfer mediators for $\mathrm{ClO}_{2}$ in acidic medium. Electrochemical reversibility of $\mathrm{ClO}_{2}$ exhibited that our Am-GC electrode provides results comparable with those of a bare GC electrode. Therefore, we need to undertake a further examination to realize a quantitatively superior analytical performance. Anyhow, our approach is highly advantageous for rapid determination of $\mathrm{ClO}_{2}$ than the bare $\mathrm{GC}$ electrode. This sensing platform is also be expected to be used for detecting trace-level concentrations of $\mathrm{ClO}_{2}$ in practical fields.

\section{Acknowledgments}

This work was supported in part by a Grant-in-Aid for Scientific Research (Grant No. 16K17923 to H.M.) from the Ministry of Education, Culture, Sports, Science and Technology (MEXT), Japan. We thank Hiroki Nihei (formerly at SIT) and Minoru Shimohori (formerly at SIT) and Masaki Hirose (formerly at SIT) for their fine contributions to this work.

\section{References}

1. G. M. Jenkins and K. Kawamura, Nature, 231, 175 (1971).

2. G. N. Kamau, Anal. Chim. Acta, 207, 1 (1988).

3. R. L. McCreery, Chem. Rev, 108, 2646 (2008).

4. A. Dekanski, J. Stevanovic, R. Stevanovic, B. Z. Nikolic, and V. M. Jovanovic, Carbon, 39, 1195 (2001).

5. Q. Zhao, Z. Zhang, L. Bao, and D. Pang, Electrochem. Commun., 10, 181 (2008).

6. R. Arrigo, M. Hävecker, S. Wrabetz, R. Blume, M. Lerch, J. McGregor, E. P. J. Parrott, J. A. Zeitler, L. F. Gladden, A. Knop-Gericke, R. Schlögl, and D. S. Su, J. Am. Chem. Soc., 132, 9616 (2010).

7. R. W. Murray, Electroanalytical Chemistry (Ed. A. J. Bard), Vol. 13, Marcel Dekker, New York, p. 191 (1984).

8. R. L. McCreery, Electroanalytical Chemistry (Ed. A. J. Bard), Vol. 17, Marcel Dekker, New York, p. 221 (1991).

9. S. M. Lyth, Y. Nabae, S. Morita, S. Kuroki, M. Kakimoto, J. Ozaki, and S. Miyata, J. Phys. Chem. C, 113, 20148 (2009).

10. S. Uchiyama, H. Watanabe, H. Yamazaki, A. Kanazawa, H. Hamana, and Y. Okabe, J. Electrochem. Soc., 154, F31 (2007).

11. A. Kanazawa, T. Okajima, S. Uchiyama, A. Kawauchi, and T. Osaka, Langmuir, 30, 5297 (2014).

12. H. Watanabe, H. Yamazaki, X. Wang, and S. Uchiyama, Electrochim. Acta, 54, 1362 (2009).

13. X. Wang, H. Watanabe, N. Sekioka, H. Hamana, and S. Uchiyama, Electroanalysis, 19, 1300 (2007).

14. E. Hayashida, Y. Takahashi, H. Nishi, and S. Uchiyama, J. Environ. Sci., 23(Suppl.), S124 (2011).

15. X. Wang, M. Xi, M. Guo, F. Sheng, G. Xiao, S. Wu, S. Uchiyama, and H. Matsuura, Analyst, 141, 1077 (2016).

16. X. Wang, T. Cao, Q. Zuo, S. Wu, S. Uchiyama, and H. Matsuura, Anal. Methods, 8, 3445 (2016).

17. E. Lynch, A. Sheerin, A. W. D. Claxson, M. D. Atherton, C. J. Rhodes, C. J. L. Silwood, D. P. Naughton, and M. Grootveld, Free Radic. Res., 26, 209 (1997).

18. H. Shimakura, N. Ogata, Y. Kawakita, K. Ohara, and S. Takeda, Mol. Phys., 111, 1015 (2013).

19. N. Ogata, M. Sakasegawa, T. Miura, T. Shibata, Y. Takigawa, K. Taura, K. Taguchi, K. Matsubara, K. Nakahara, D. Kato, K. Sogawa, and H. Oka, Pharmacology, 97, 301 (2016).

20. N. Ogata, Biochemistry, 46, 4898 (2007).

21. D. E. Cortezzo, K. Koziol-Dube, B. Setlow, and P. Setlow, J. Appl. Microbiol., 97, 838 (2004).

22. M. E. Alvarez and R. T. O'Brien, Appl. Environ. Microbiol., 44, 1064 (1982).

23. N. Ogata and T. Shibata, J. Gen. Virol., 89, 60 (2008).

24. A. E. Gorbalenya, S. C. Baker, R. S. Baric, R. J. de Groot, C. Drosten, A. A. Gulyaeva, B. L. Haagmans, C. Lauber, A. M. Leontovich, B. W. Neuman, D. Penzar, S. Perlman, L. L. M. Poon, D. Samborskiy, I. A. Sidorov, I. Sola, and J. Ziebuhr, bioRxiv, doi:10.1101/2020.02.07.937862.

25. J. Tkáčová and J. Božíková, Slovak J. Civ. Eng., 22(2), 21 (2014).

26. G. Valensi, E. Deltombe, N. D. E. Zoubov, C. Vanleugenhaghe, and M. Pourbaix, Atlas of Electrochemical Equilibria in Aqueous Solutions (Second English Edition) (Translated from the French by J. A. Franklin), Section 20.2, NACE International and Cebelcor, Brussels, p. 590 (1974). 